\title{
Atresia of right pulmonary veins and anomalous left pulmonary venous drainage into portal circulation
}

\author{
M. ŠAMÁNEK, S. T U゚MA, D. BENEŠOVÁ, V. POVÝS̆LOVÁ, \\ F. PRAŽSKÝ, and E. Č́POVÁ \\ Cardiopulmonary Laboratory, University Hospital Motol and Departments of Paediatrics and \\ Pathology, Faculty of Paediatrics, Charles University, Prague, Czechoslovakia
}

\begin{abstract}
Šamánek, M., Tůma, S., Benešová, D., Povýšilová, V., Pražský, F., and Čápová, E. (1974). Thorax, 29, 446-450. Atresia of right pulmonary veins and anomalous left pulmonary venous drainage into portal circulation. An anomaly of pulmonary venous drainage in a male newborn infant is described whereby the left pulmonary veins entered the portal vein and the right pulmonary veins were atretic. A correct diagnosis was made by detecting high-oxygen saturation in the hepatic veins, right-to-left shunt at atrial level, and increased pulmonary artery wedge pressure in comparison with the left atrial pressure, and was confirmed by angiography.
\end{abstract}

Atresia of one pulmonary vein or of the common pulmonary vein is an extremely rare condition. Postmortem findings in two cases of pulmonary venous atresia were described by Benešová (1955). Pulmonary veins converged to form a trunk which terminated as a capillary network in the posterior mediastinum, obviously representing a collateral route. Lucas et al. (1962) reported three similar cases of pulmonary venous atresia diagnosed at necropsy.

The present report concerns an infant with atresia of the right pulmonary veins, and anomalous drainage of the left pulmonary veins into the portal circulation, diagnosed during life. To our knowledge no case identical with this one has been reported.

\section{CASE REPORT}

J. B., a male infant of young parents, was born spontaneously following a 34-week gestational period complicated by eclampsia. The birth weight and length were $2,000 \mathrm{~g}$ and $48 \mathrm{~cm}$. Cyanosis and tachypnoea were the first symptoms noticed shortly after birth. The child was referred immediately to the Department of Paediatrics at the district hospital.

On admission he was cyanotic with a respiratory rate of $80 / \mathrm{min}$ and pulse rate of $154 / \mathrm{min}$. Fine moist râles were detected at the base of the right lung. There was no audible heart murmur. The liver was not enlarged. Acidosis with reduction of standard bicarbonate and increased $\mathrm{PCO}_{2}$ was corrected, but mild acidosis of the 'respiratory type' persisted (Table I). The chest radiograph showed a normal
T A B L E I

BLOOD GAS TENSION AND ACID-BASE EQUILIBRIUM

\begin{tabular}{c|ccc|c|cc}
\hline $\begin{array}{c}\text { Age } \\
\text { (weeks) }\end{array}$ & $\begin{array}{c}\mathrm{PCO}_{2} \\
\text { (torr) }\end{array}$ & $\begin{array}{c}\mathrm{PO}_{2} \\
\text { (torr) }\end{array}$ & $\begin{array}{c}\mathrm{SO}_{2} \\
\%\end{array}$ & pH & & \multicolumn{2}{|c}{ Bicarbonates (mEq/l) } \\
& 69 & - & - & $7 \cdot 200$ & $18 \cdot 7$ & $26 \cdot 3$ \\
4 & 43 & 52 & 77 & $7 \cdot 222$ & 16.2 & $17 \cdot 1$ \\
6 & 57 & 40 & 68 & 7.308 & 24.4 & $28 \cdot 0$ \\
7 & 61 & 50 & 80 & $7 \cdot 308$ & $25 \cdot 5$ & $30 \cdot 1$ \\
\hline
\end{tabular}

cardiac silhouette. Increased density and diffuse granular opacification throughout the right lung field contrasted with the normal appearance of the left lung. During the first three weeks the condition improved slightly. Unilateral neonatal pneumonia was diagnosed clinically and the patient was treated with antibiotics and oxygen.

The clinical condition deteriorated progressively at the end of the third week of life and the infant was admitted to the University Hospital Motol. The child was mildly cyanotic and dyspnoeic, the respiratory rate was about $90 / \mathrm{min}$ and the heart rate $150 / \mathrm{min}$. The peripheral pulses were normal. Inspiratory and expiratory moist râles spread from the base to the whole right lung. Normal auscultatory findings persisted in the left lung. The first heart sound was normal in intensity and the second sound was accentuated at the upper left sternal border. A soft grade $2 / 6$ ejection systolic murmur was heard in the second to third left intercostal space at the sternal border. The liver was palpable $4 \mathrm{~cm}$ below the right costal margin. 
Electrocardiograms obtained up to the fourth week of life did not differ from normal. At the sixth week the frontal $\mathrm{QRS}$ axis was $+104^{\circ}$, and a mild right ventricular hypertrophy was noted without any $P$ wave abnormality (Fig. 1).

Multiple chest radiographs did not reveal any cardiac enlargement (Fig. 2). Increased density and diffuse granular opacification in the right lung was a permanent finding. The right cardiac border was obscured and distinct Kerley B lines were revealed in the right costophrenic angle. The right pulmonary artery and its branches were not visible. The radiographic appearance of the left lung differed from that of the right lung. The pulmonary vascular markings were abundant, especially in the hilar region. The left lung was more radiolucent than the right and had a reticular rather than granular pattern. Kerley $B$ lines were absent. The liver shadow was enlarged.

Lung scanning demonstrated a marked decrease in the right pulmonary blood flow (Fig. 3). The perfusion of the left lung was evenly distributed.

Blood gas tension and acid-base equilibrium were repeatedly abnormal (Table I) with a tendency to a
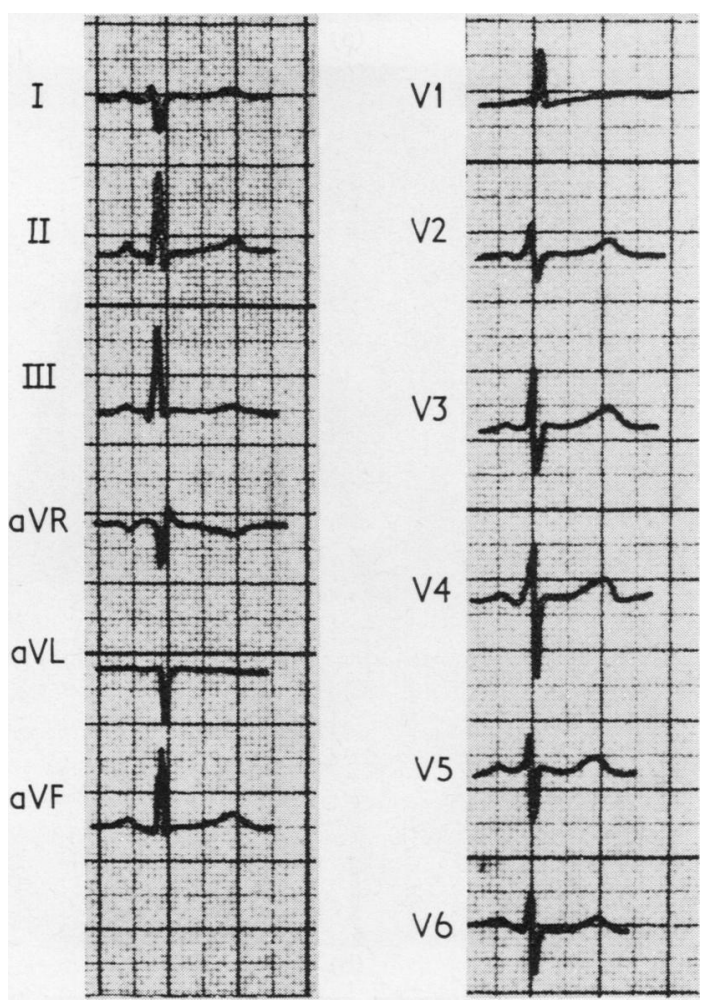

FIG. 1. Electrocardiogram, aged 6 weeks.

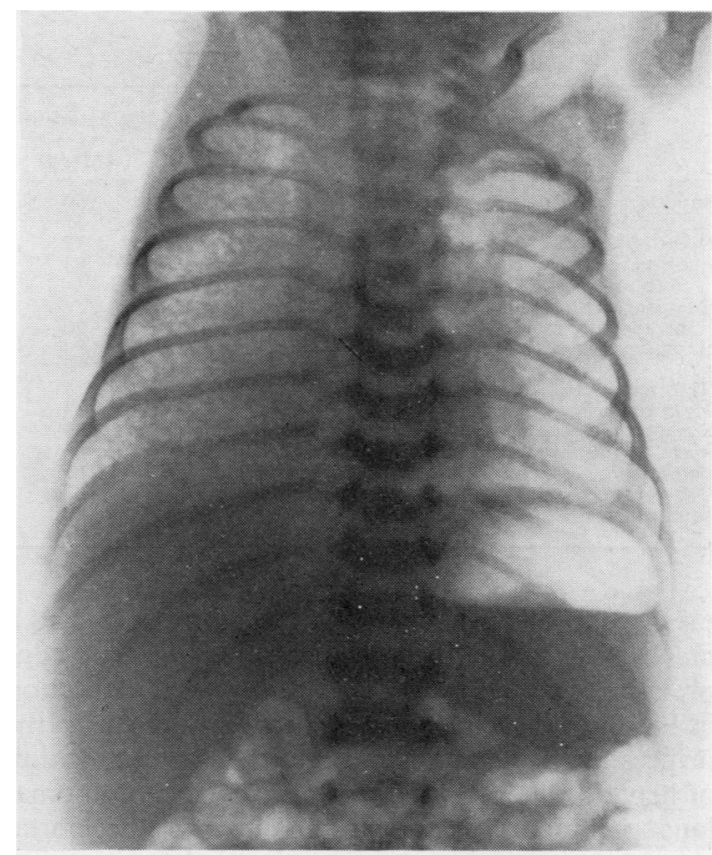

FIG. 2. Plain chest radiograph, aged 4 weeks. For description, see text. Distinct Kerley $B$ lines were seen only on the original $\mathrm{x}$-ray picture.

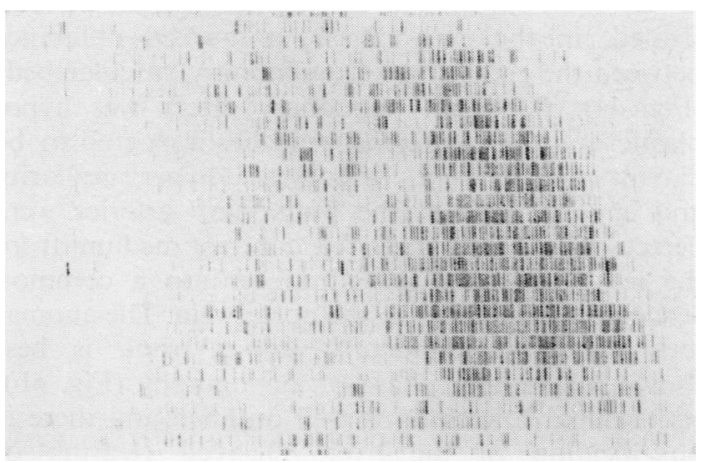

FIG. 3. Lung scan, aged 5 weeks. Macroaggregated human serum albumin tagged with technetium-99m was given intravenously in a dose of $50 \mu \mathrm{Ci}$. The distribution of radioactivity was detected by Pho/Dot II rectilinear scanner (Nuclear, Chicago) equipped with a 127-hole collimator. For description, see text.

progressive increase of the $\mathrm{PCO}_{2}$ value. Other laboratory tests were normal.

Cardiac catheterization was performed through the right saphenous vein (Table II). The pressure tracings showed pulmonary arterial hypertension of the third grade, elevation of the right atrial 
T A B L E I I CARDIAC CATHETERIZATION FINDINGS

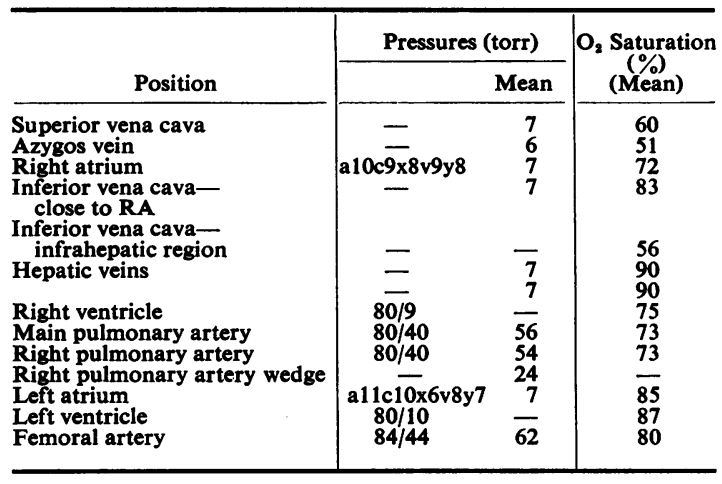

pressure to the level of the left atrial pressure, and a marked increase of the right pulmonary artery wedge pressure. The difference in blood oxygen saturation in the inferior vena cava proximal and distal to the orifices of the hepatic veins and the $90 \%$ saturation of hepatic venous blood were suggestive of anomalous pulmonary venous drainage into the portal circulation. Oxygen saturation in the left heart was higher than in the right atrium and ventricle. An attempt to enter the pulmonary veins from the left atrium was not successful.

The right ventricular biplane angiogram demonstrated, in the early phase, a marked difference between the right and left pulmonary vascular beds (Fig. 4a). The right pulmonary artery was hypoplastic and the peripheral branches appeared to be narrow and deficient. In contrast, hypervascularity and engorgement of the pulmonary arteries were detected in the left lung. The contrast medium from the left pulmonary veins drained into a common vertical channel entering the portal vein. The anomalous common pulmonary venous trunk is best shown in the later phase of angiography (Fig. 4b). Its terminal branching is well outlined and there is opacification of the liver. Delayed clearing of contrast medium from both pulmonary vascular beds, and particularly from the right pulmonary artery, was observed. A narrowing at the site of the entrance of the pulmonary venous trunk into the portal vein was not seen.

Regional lung volume studied by a modification of xenon-133 equilibration technique (Ball, Stewart, Newsham, and Bates, 1962; Ruth and Samánek, 1973) was lower in the right lung than in the corresponding zones of the left lung (Fig. 5; Table III). The volume of the lower regions was less than that of the upper regions in both lungs. Radioactive gas washout was faster in the right lung than in the left. There was only

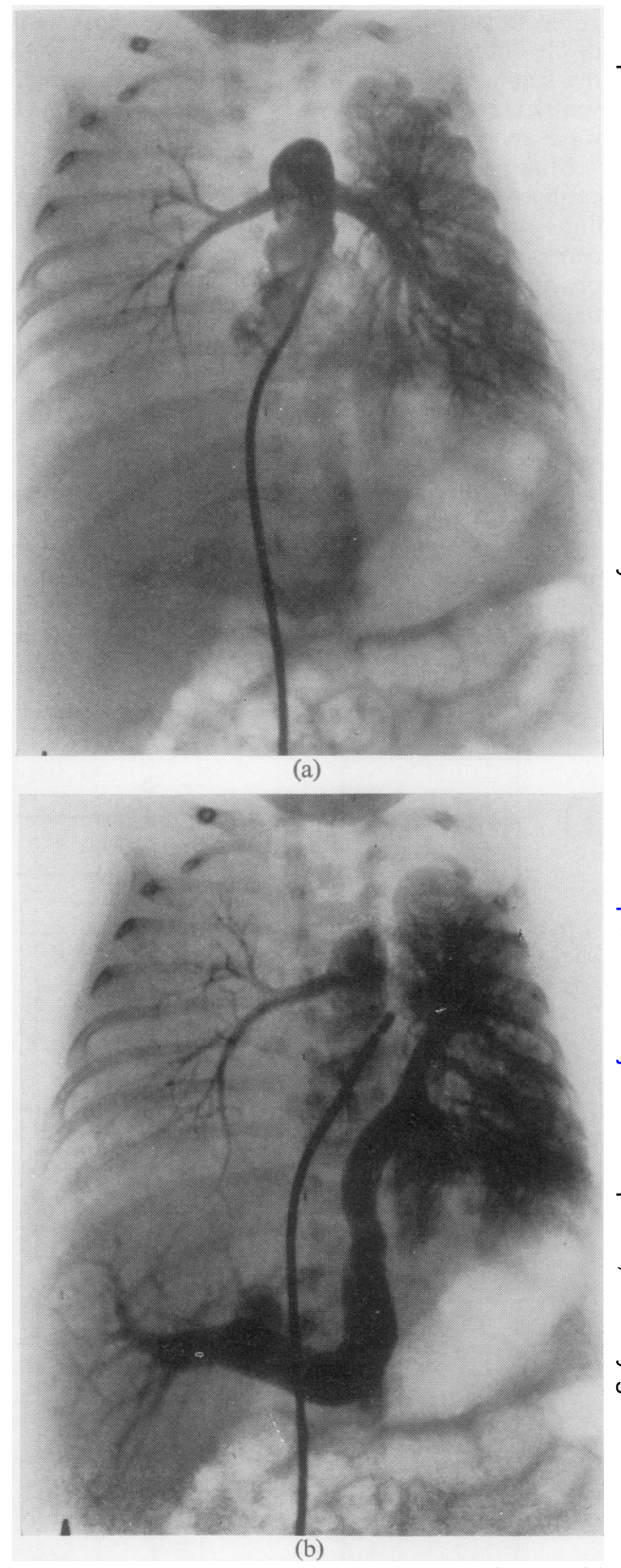

FIG. 4. Right ventricular angiogram, frontal view: (a) early phase; (b) later phase. For description see text. 


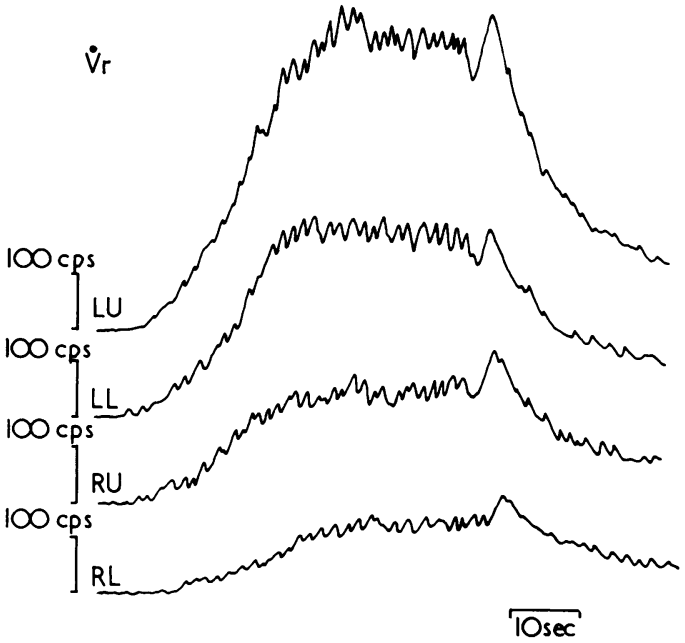

FIG. 5. Xenon-133 scintigraphy. Rebreathing of oxygen labelled with $0.5 \mu \mathrm{Ci}{ }^{133} \mathrm{Xe}$ per litre in a closed system equipped with a $\mathrm{CO}_{2}$ absorber. Regional radioactivity after equilibration is proportional to the volume of the airspaces under the detectors communicating with the atmosphere. Coupled detectors of $\frac{1}{2}$-inch diameter were located in the centre of the upper and lower halves of both lungs. After equilibrium was reached the patient was switched to the inhalation of air, and the regional washout curves of ${ }^{133} \mathrm{Xe}$ were recorded.

T A B L E I I I

REGIONAL DISTRIBUTION OF LUNG VOLUME AND VENTILATION

\begin{tabular}{l|c|c}
\hline \multicolumn{1}{c|}{ Lung Region } & $\begin{array}{c}\text { Lung Volume } \\
\text { (\% of total) }\end{array}$ & $\begin{array}{c}\text { Washout Half-time } \\
\text { (seconds) }\end{array}$ \\
\cline { 1 - 3 } Right upper & 17 & $7 \cdot 3$ \\
lower & 10 & $7 \cdot 8$ \\
upper & 44 & $10 \cdot 8$ \\
lower & 29 & $10 \cdot 4$ \\
\hline
\end{tabular}

an insignificant difference between the individual regions within one lung.

On the basis of the clinical picture, catheterization data, chest radiographs, and angiography, a diagnosis was made of right pulmonary venous atresia, anomalous drainage of the left pulmonary veins into the portal vein, and interatrial communication. Surgical intervention was not recommended because of the unfavourable prognosis of the combination of anomalous pulmonary venous drainage and atresia.

The infant died at the age of 7 weeks. At necropsy the heart was normal in size and weight. The right atrium and ventricle, the superior and inferior venae cavae, all valves, and the position of the great arteries did not exhibit any abnormality. The ductus arteriosus was contracted. A widely patent foramen ovale enabled good communication between the right and left heart. The left atrium was hypoplastic and the left ventricle was slightly smaller than the right ventricle. The right pulmonary artery was narrow. A common pulmonary venous trunk emerging from the left lung descended in the posterior mediastinum to the diaphragm and passed through the oesophageal hiatus to terminate in the portal vein (Fig. 6). The right pulmonary veins converged to form a common trunk leading from the right lung, passing beneath the right pulmonary artery towards the left main bronchus. From a blind recess on the end of the trunk only, several small vessels disappearing in the mediastinal tissue were identified. Macroscopically there was a honeycomb appearance of the right lung due to multiple holes formed by cystic lymphangiectases. Prominence of the dilated lymphatics was evident on inspection of the pleural surface of both lungs. Histologically, dilated cystic

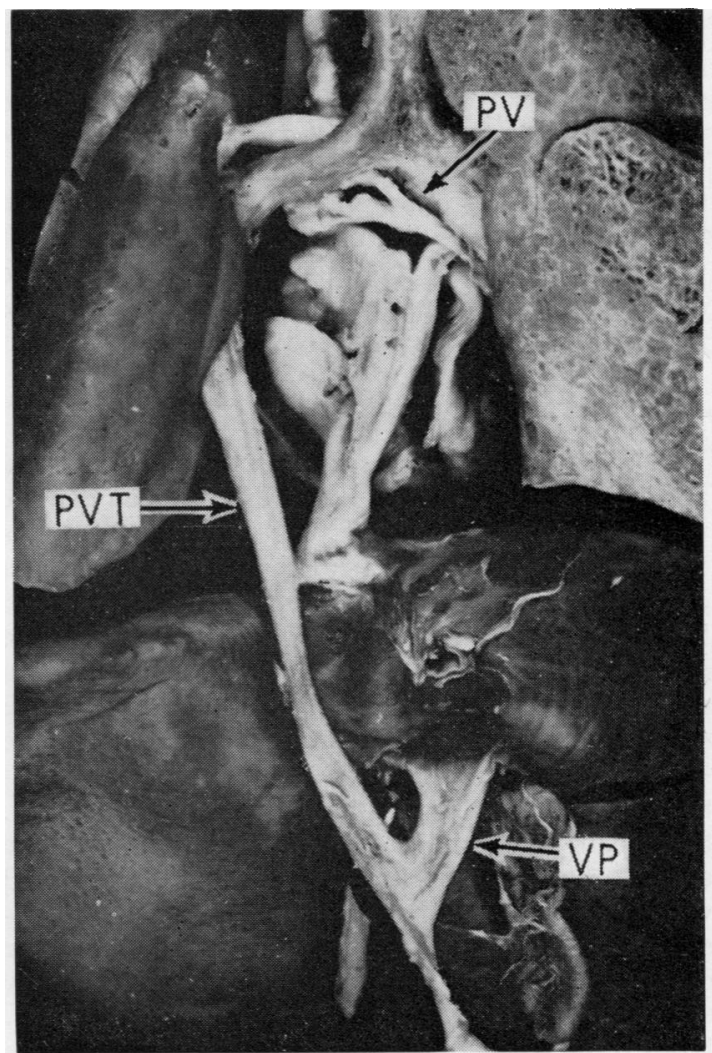

FIG. 6. Posterior view of the specimen demonstrates the pulmonary venous trunk (PVT) entering the portal vein $(V P)$. Right pulmonary veins $(P V)$ end as a blind recess. Note the appearance of the lungs. For details, see text. 


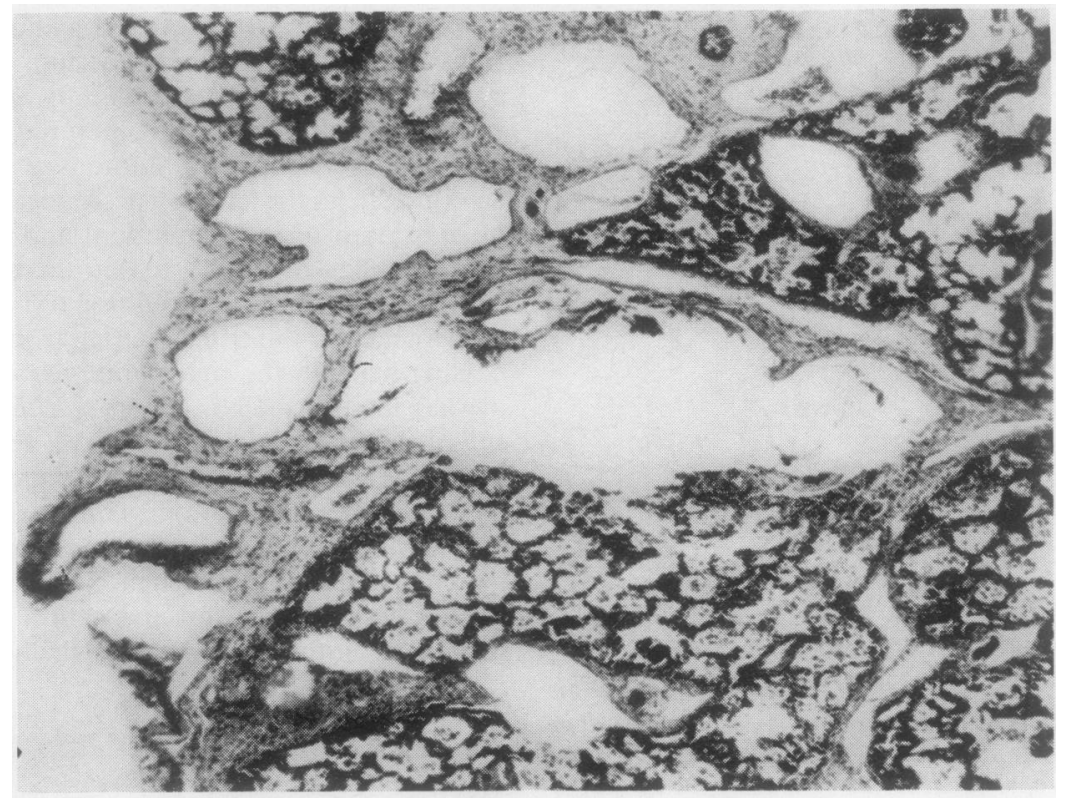

FIG. 7. Microscopic section of subpleural tissue in right lung showing dilated lymphatic spaces and thickening of interlobular connective tissue $(\times 120)$.

lymphatics were found mostly under the visceral pleura and along the bronchi in the thickened peribronchial tissue (Fig. 7). All changes were developed more in the right lung than in the left. The liver was enlarged and its weight was increased.

\section{COMMENTS}

Recent advances in the surgical correction of total anomalous pulmonary venous drainage emphasize the importance of an early precise diagnosis of this malformation. In our patient the delay in making a correct diagnosis was due mainly to the difference in the auscultatory and $x$-ray findings between the right and left lung, supporting the diagnosis of a unilateral pneumonia. The decreased volume of the patent airspaces in the right lung as compared with the left lung can be explained by pulmonary venous atresia leading to unilateral pulmonary oedema. Significant unilateral or regional obstruction of the airways could be excluded by evaluating regional washout curves. Higher pulmonary vascular resistance in the right than in the left lung was thought to be responsible for the abnormal pulmonary blood flow distribution proved by the isotope techniques. However, lung scanning was not able to differentiate between precapillary and postcapillary pulmonary vascular obstruction. The definite diagnosis was made by cardiac catheterization and angiography. An interesting finding at catheterization was the preferential distribution of the inferior vena caval $\stackrel{\circ}{\Phi}$ blood to the left atrium which maintained arterial $\Rightarrow$ blood saturation at about $80 \%$. High postcapillary resistance was indicated by elevation of the pulmonary wedge pressure. An obstruction in the heart was excluded by the normal values of the left atrial and ventricular pressures. The localization of the resistance in the hepatic circulation as well as the precise anatomic diagnosis were made by angiography.

\section{REFERENCES}

Ball, W. C., Stewart, P. B., Newsham, L. G. S., and o Bates, D. V. (1962). Regional pulmonary function studied with xenon 133. Journal of Clinical Investiga- $-\frac{1}{O}$ tion, 41, 519.

Benešová, D. (1955). Congenital anomalous drainage of $\tilde{N}$ the pulmonary veins. Časopis lékařu Českých, 94, 107. N (English summary)

Lucas, R. V. Woolfrey, B. F., Anderson, R. C., Lester, R. G., and Edwards, J. E. (1962). Atresia of the common pulmonary vein. Pediatrics, 29, 729.

Ruth, C. and Samánek, M. (1973). Investigation of regional lung function using stationary radiation ? detectors. In Investigation of the Regional Lung Function, edited by M. Samánek, pp. 51-58. Czecho- $\frac{\vec{D}}{\mathrm{D}}$

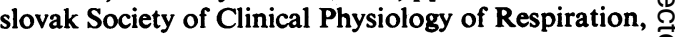
Karlovy Vary.

Requests for reprints to: Dr. Milan Samánek, University Hospital Motol, 15006 Prague, Czechoslovakia. 